\title{
A new spallation mechanism of thermal barrier coatings and a generalized mechanical model
}

\author{
Bo Yuan ${ }^{\mathrm{a}}$, Christopher M. Harvey ${ }^{\mathrm{a}}$, Rachel C. Thomson ${ }^{\mathrm{b}}$, \\ Gary W. Critchlow ${ }^{\mathrm{b}}$, David Rickerby ${ }^{\mathrm{c}}$ and Simon Wang, ${ }^{\mathrm{a}, \mathrm{d}, *}$ \\ ${ }^{a}$ Department of Aeronautical and Automotive Engineering, Loughborough University, \\ Loughborough, Leicestershire LE11 3TU, UK \\ ${ }^{b}$ Department of Materials, Loughborough University, \\ Loughborough, Leicestershire LE11 3TU, UK \\ ${ }^{c}$ Surface Engineering Precision Institute, Cranfield University, \\ Cranfield, Bedfordshire MK43 OAL, UK
}

${ }^{d}$ School of Mechanical and Equipment Engineering, Hebei University of Engineering, Handan 056038, China

\begin{abstract}
Multilayer thermal barrier coating (TBC) systems typically consist of three layers of materials: A thermal barrier top coat (TC), a thermally-grown oxide (TGO), and a bond coat (BC) in addition to the substrate. Local strain energy concentrations, called 'pockets of energy concentration (PECs)' in this work, often occur around the interface between the TGO and the BC. They have various causes, including local phase changes, and non-uniform creep and plastic relaxation. It is discovered that both PECs and buckling drive the spallation of a TBC in a new spallation mechanism. A PEC-based mechanical model is developed that describes, explains and predicts how blisters nucleate in a TBC under constant biaxial compressive residual stress, steadily and then unsteadily grow, and finally spall off. Two conditions are established for the occurrence of TBC spallation, which depend on the compressive residual strain energy density in the $\mathrm{TC}$ and the $\mathrm{TGO}$, and the interface fracture toughness. Experimental validation of the model was performed using aircraft jet engine turbine blades with electron beam physical vapor deposition (EBPVD) TBCs. The predictions from the developed PEC-based mechanical model for the radii of spallation in the TBC are in a good agreement with experiment results.
\end{abstract}

Keywords: Interface fracture toughness; Pockets of energy concentration; Spallation; Thermal barrier coatings (TBC)

\footnotetext{
* Corresponding Author

Email addresses: S.Wang@lboro.ac.uk (S. Wang), B.Yuan@lboro.ac.uk (B. Yuan),

C.M.Harvey@lboro.ac.uk (C. M. Harvey), R.C.Thomson@lboro.ac.uk (R. C. Thomson),

G.W.Critchlow@1boro.ac.uk (G. W. Critchlow), David.Rickerby@cranfield.ac.uk (D. Rickerby)
} 


\section{Nomenclature}

$\begin{array}{ll}A, B, D & \text { Extensional, coupling and bending stiffness } \\ A_{x} & \text { Amplitude of upward deflection of coating blister } \\ b & \text { Width of straight blisters } \\ E & \text { Young's modulus } \\ G, G_{\mathrm{I}}, G_{\mathrm{II}} & \text { Total, mode I and mode II energy release rates } \\ G_{\mathrm{Ic}}, G_{\mathrm{II}} & \text { Mode I and II interface fracture toughness } \\ G_{\mathrm{c}} & \text { Interface fracture toughness } \\ \bar{G}_{\mathrm{c}} & \text { Average fracture toughness over interface } \\ M_{x \mathrm{~B}}, N_{x \mathrm{~B}} & \text { Crack tip bending moment and effective force } \\ M_{x}^{\mathrm{R}}, N_{x}^{\mathrm{R}} & \text { Relaxation bending moment and effective force } \\ h & \text { Thickness of thermal barrier coating } \\ R_{\mathrm{B}} & \text { Half-width of straight blisters; radius of circular blisters } \\ U_{\mathrm{a}} & \text { Blister energy } \\ U_{\mathrm{s}} & \text { Blister interface surface energy } \\ U_{0} & \text { Blister residual strain energy } \\ w & \text { Blister upward deflection } \\ x, y & \text { Lengthwise and widthwise coordinates of straight blisters } \\ z & \text { Out-of-plane coordinate } \\ r, \theta & \text { Radial and circumferential coordinates of circular blisters } \\ \alpha & \text { Buckling correction factor } \\ \varepsilon^{\mathrm{R}}, \sigma^{\mathrm{R}} & \text { Relaxation strain and stress due to bending deflection } \\ \varepsilon^{0}, \sigma^{0} & \text { Residual compressive strain and stress in thermal barrier coating } \\ v & \text { Poisson's ratio } \\ \xi & \text { Measure of anisotropic coupling, } \xi=\left(A D-B^{2}\right) /(2 A D) \\ \psi & \text { Ratio of interface mode II and I fracture toughness } \\ & \end{array}$

Abbreviations

BC

Bond coat

CTE

Coefficient of thermal expansion

EBPVD

Electron beam physical vapor deposition

ERR

Energy release rate

PEC

Pocket of energy concentration

TBC

Thermal barrier coating

TC

Top coat

TGO

Thermally grown oxide

YSZ

Yttria-stabilized zirconia 


\section{Introduction}

Thermal barrier coating (TBC) material systems protect aero-engine components from the high and prolonged heat loads and improve engine durability and energy efficiency. A TBC material system is typically constructed from an yttria-stabilized zirconia (YSZ) ceramic top coat (TC) of low thermal conductivity, an MCrAlY overlay or diffusion bond coat (BC) that adheres the TC to an alloy substrate, and a thermally grown oxide (TGO) layer that forms at the interface between the TC and the BC at elevated temperature. Spallation failure, in which the TC detaches from the BC during service, has stimulated enormous research effort to understand the complex mechanisms driving the failure. Interested readers are referred to Refs. $[1,2]$ for more information. The present work focuses on reporting a new mechanism of TBC spallation and on developing a mechanical model to describe, explain and predict the spallation behavior.

The TGO layer significantly reduces the adhesion toughness between the TC and the BC $[3,4]$. In addition, the large mismatch of coefficients of thermal expansion (CTEs) between the TGO and the $\mathrm{BC}$ results in a large compressive residual stress in the TGO layer during cooling. This very high compressive strain energy density in the TGO layer is therefore considered [2,5] to be a major cause of coating spallation. Moreover, local effects are also expected, with local strain energy concentrations around the TGO/BC interface. These local effects can be ascribed to various causes, including the existence of defects [6], non-uniform plastic and creep relaxation [7], the local roughness [8,9], the local phase changes [10], and local grain size and grain boundary changes [11]. The high compressive strain energy density and local effects together give rise to the aforementioned new mechanism of TBC spallation.

It is worth reviewing two recent studies $[12,13]$ that are pertinent to the present work, in which the room-temperature spallation (i.e. spallation under constant biaxial compressive residual stress) of a single layer of $\alpha$-alumina grown by oxidation on a $\mathrm{Fe}-\mathrm{Cr}$-Al alloy substrate is studied. The authors of these two studies, Wang, Harvey and Wang, reported that pockets of energy concentration (PECs) can exist in the form of pockets of tensile stress and shear stress in and around the interface between the TGO and the substrate. The origins of PECs were not determined in Refs. [12,13]; instead, the existence of PECs was taken as given and then the mechanical consequences for spallation behavior was predicted. Nevertheless, it was hypothesized that PECs can be caused by dynamic and non-uniform creep or plastic relaxation, or by thermal, chemical, or other processes. Based on this understanding of PECs, a mechanical model was developed which captured the entire process from nucleation to spallation and 
which showed excellent agreement with the experimental measurements of circular blister spallation in Refs $[14,15]$. In contrast, the traditional buckling-driven approach, which assumes a pre-existing circular separation with a critical size slightly larger than the buckling size, cannot capture what is observed in these experiments [14,15]. Instead, the observed size of the $\alpha$-alumina blister in nucleation and earlier stable growth stage is much smaller than the critical buckling size, which requests a significant amount of extra energy independent of the residual strain energy. It was therefore concluded that the PEC-based mechanical model $[12,13]$ works very well while the traditional buckling-driven model does not.

The original contributions of this work are in (1) developing a PEC-based mechanical model to predict the spallation behavior of multilayer TBC material systems with variable material properties through the thickness of each layer under constant biaxial compressive residual stresses; and (2) conducting experimental tests to observe the spallation of TBCs under the same conditions. An additional aim of the work is to inform researchers in the field about this new mechanism of TBC spallation and to thereby promote wider research on the causes of PECs, resulting in design improvements for TBC material systems. Note that, again, the origins of PECs are not explicitly considered in this work, although the probable causes have been mentioned above. Determination of the causes of PECs is an enormous task that is much beyond the scope of the present work; however, regardless of their cause, it is still possible to establish the mechanical consequences of their existence.

The outline of the paper is as follows: PEC mechanical models are developed in Sections 2 and 3 for straight and circular blisters respectively. Both blister shapes have been observed in TBCs. Comparisons between model predictions and experimental results are given in Section 4. Conclusions are given in Section 5.

\section{PEC-based mechanical model for straight blisters in multilayer TBCs}

Figure 1 depicts a multilayer TBC with a straight blister of width $2 R_{\mathrm{B}}$, blister thickness $h$ , length $b$, and height $A_{x}$. It is assumed that the blister consists of the TC and TGO, which are represented by the light and dark layer respectively. That is, the delamination is assumed to be on the TGO/BC interface, as is usually observed in experiments with EBPVD TBCs. Due to the assumed delamination location, in the following the TC and TGO are referred to collectively as the 'top', and the BC and substrate are referred to collectively as the 'bottom'. Note that despite this assumption, the model developed here is generally applicable to other multilayer material systems and other crack locations. 


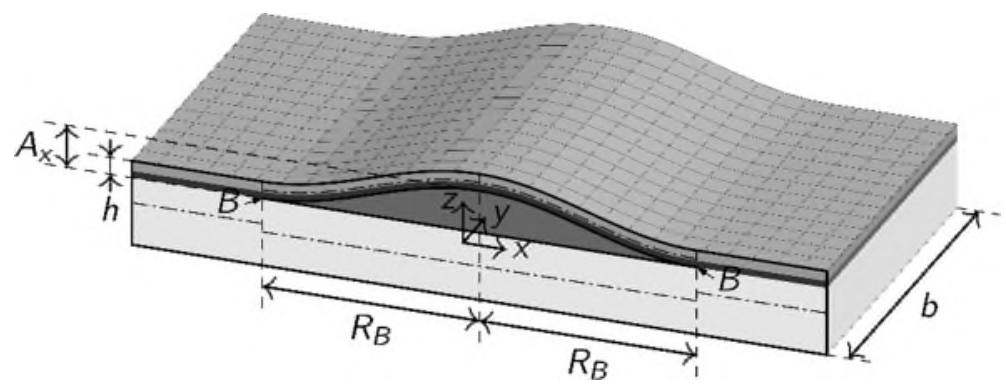

Figure 1 A straight coating blister.

The axes in Figure 1 show only the directions and not the origin. Following the convention of classical laminate theory, the origin of the $z$ axis for the top is at its middle plane (that is, at the middle plane of the TC and TGO together). Likewise, the origin of the $z$ axis for the bottom is at the middle plane of the substrate and $\mathrm{BC}$ together.

\subsection{Residual stresses before delamination}

Since the thickness of the bottom is much greater than the thickness of the top; therefore, the biaxial compressive stress in the bottom is approximately zero after cooling by $\Delta T_{\text {bot }}(z)$. Consequently, the total residual strain in the bottom consists only of thermal strain, which can be approximated as its average quantity over the thickness, as follows:

$$
\varepsilon_{\mathrm{bot}}=\int_{-h_{\mathrm{bot}} / 2}^{h_{\mathrm{bot}} / 2} C_{\mathrm{bot}}(z) \Delta T_{\mathrm{bot}}(z) d z / h_{\mathrm{bot}}
$$

where $h_{\text {bot }}$ and $C_{\text {bot }}(z)$ are the thickness and CTE of the bottom respectively.

Assuming that the top and bottom are perfectly bonded prior to delamination, the top will contract by the same amount as the bottom $\varepsilon_{\text {bot }}$ as they are cooled from temperature $T_{0}(z)$ to $T$ with $\Delta T(z)=T-T_{0}(z)$. The biaxial residual compressive stress $\sigma^{0}(z)$ in the top at temperature $T$ is therefore

$$
\sigma^{0}(z)=\frac{E(z)}{1-v(z)}\left[\varepsilon_{\text {bot }}-\varepsilon^{\mathrm{T}}(z)\right]
$$

where $\varepsilon^{\mathrm{T}}(z)=C(z) \Delta T(z)$ represents the free thermal strain in the top due to the CTE $C(z)$ and cooling $\Delta T(z)$. The Young's modulus and Poisson's ratio of the top are $E(z)$ and $v(z)$ respectively; they are considered uniform in plane, but vary along the $z$ axis. 
In Eq. (2), $\varepsilon^{\mathrm{T}}(z)$ can be expressed as the superposition of a uniform $\varepsilon^{\mathrm{T}}(0)$, which is the value at the middle plane of the top, and a relative value $\Delta \varepsilon^{\mathrm{T}}(z)$, that is,

$$
\varepsilon^{\mathrm{T}}(z)=C(z) \Delta T(z)=\varepsilon^{\mathrm{T}}(0)+\Delta \varepsilon^{\mathrm{T}}(z)
$$

Now, substituting Eq. (3) into Eq. (2) gives

$$
\sigma^{0}(z)=\frac{E(z)}{1-v(z)}\left\{\varepsilon_{\text {bot }}-\left[\varepsilon^{\mathrm{T}}(0)+\Delta \varepsilon^{\mathrm{T}}(z)\right]\right\}=\frac{E(z)}{1-v(z)} \varepsilon^{0}(z),
$$

where $\varepsilon^{0}(z)$ is the biaxial compressive residual strain in the top. For concise notation, let $\varepsilon^{0}$ denote $\varepsilon^{0}(0)$ or equivalently $\varepsilon_{\text {bot }}-\varepsilon^{\mathrm{T}}(0)$. Now, the biaxial compressive residual stress $\sigma^{0}(z)$ in the top can be expressed in the following form:

$$
\sigma^{0}(z)=\frac{E(z)}{1-v(z)}\left[\varepsilon^{0}-\Delta \varepsilon^{\mathrm{T}}(z)\right] .
$$

Then, the resultant compressive residual force per unit width and bending moment per unit width are calculated as

$$
N^{0}=\int_{-h / 2}^{h / 2} \sigma^{0}(z) d z=A^{*} \varepsilon^{0}-\Delta N^{\mathrm{T}}
$$

and

$$
M^{0}=\int_{-h / 2}^{h / 2} \sigma^{0}(z) z d z=B^{*} \varepsilon^{0}-\Delta M^{\mathrm{T}}
$$

where

$$
A^{*}=\int_{-h / 2}^{h / 2} \frac{E(z)}{1-v(z)} d z \quad \text { and } \quad B^{*}=\int_{-h / 2}^{h / 2} \frac{E(z)}{1-v(z)} z d z
$$

and

$$
\Delta N^{\mathrm{T}}=\int_{-h / 2}^{h / 2} \frac{E(z)}{1-v(z)} \Delta \varepsilon^{\mathrm{T}}(z) d z \quad \text { and } \quad \Delta M^{\mathrm{T}}=\int_{-h / 2}^{h / 2} \frac{E(z)}{1-v(z)} \Delta \varepsilon^{\mathrm{T}}(z) z d z .
$$

Note that $\Delta N^{\mathrm{T}}$ and $\Delta M^{\mathrm{T}}$ in Eq. (9) are the resultant thermal force per unit width and thermal bending moment per unit width respectively due to $\Delta \varepsilon^{\mathrm{T}}(z)$ in Eq. (3). Furthermore, Eqs. (6) and (7) show that the residual loads in the top are increased for negative $\Delta \varepsilon^{\mathrm{T}}(z)$. This can be caused by TGO growth, sintering of the TC, etc. 


\subsection{Stresses after delamination}

After delamination, the shape of the blister as shown in Figure $\mathbf{1}$ is assumed to be sinusoidal $[12,13]$, that is,

$$
w(x)=\frac{A_{x}}{2}\left[1+\cos \left(\frac{\pi x}{R_{\mathrm{B}}}\right)\right],
$$

from which the curvature $\kappa$ of the upward bending is

$$
\kappa=\frac{d^{2} w}{d x^{2}}=-\frac{A_{x} \pi^{2}}{2 R_{\mathrm{B}}^{2}} \cos \left(\frac{\pi x}{R_{\mathrm{B}}}\right) .
$$

Then the relaxation strains in the blister due to the upward bending, $\varepsilon_{x}^{\mathrm{R}}(z)$ and $\varepsilon_{y}^{\mathrm{R}}(z)$, based on classical plate theory, are

$$
\varepsilon_{x}^{\mathrm{R}}(z)=\varepsilon_{x}^{\mathrm{R}}(0)-z \frac{d^{2} w}{d x^{2}} \quad \text { and } \quad \varepsilon_{y}^{\mathrm{R}}(z)=0 .
$$

Note that the relaxation strain is plane strain, which results in $\varepsilon_{y}^{\mathrm{R}}(z)=0$ in Eq. (12). The quantity $\varepsilon_{x}^{\mathrm{R}}(0)$ in Eq. (12) is the relaxation strain at the middle surface of the blister and can be calculated based on the conventional von Kármán geometric nonlinearity approach [13] as

$$
\varepsilon_{x}^{\mathrm{R}}(0)=\varepsilon_{x}^{\mathrm{R}}=\frac{1}{2 R_{\mathrm{B}}} \int_{0}^{R_{\mathrm{B}}}\left(\frac{d w}{d x}\right)^{2} d x=\left(\frac{\pi A_{x}}{4 R_{\mathrm{B}}}\right)^{2} .
$$

The relaxation stresses $\sigma_{x}^{\mathrm{R}}(z)$ and $\sigma_{y}^{\mathrm{R}}(z)$ are then calculated as

$$
\sigma_{x}^{\mathrm{R}}(z)=\frac{E(z)}{1-v^{2}(z)} \varepsilon_{x}^{\mathrm{R}}(z) \quad \text { and } \quad \sigma_{y}^{\mathrm{R}}(z)=v(z) \sigma_{x}^{\mathrm{R}}(z),
$$

which are positive in tension. The relaxation force per unit width and bending moment per unit width in the blister are calculated by using Eqs. (11) to (14) as

$$
N_{x}^{\mathrm{R}}=\int_{-h / 2}^{h / 2} \sigma_{x}^{\mathrm{R}}(z) d z=A \varepsilon_{x}^{\mathrm{R}}-B \kappa
$$

and

$$
M_{x}^{\mathrm{R}}=\int_{-h / 2}^{h / 2} \sigma_{x}^{\mathrm{R}}(z) z d z=B \varepsilon_{x}^{\mathrm{R}}-D \kappa,
$$

where the extensional stiffness $A$, coupling stiffness $B$ and bending stiffness $D$ are defined as 


$$
A=\int_{-h / 2}^{h / 2} \frac{E(z)}{1-v^{2}(z)} d z, \quad B=\int_{-h / 2}^{h / 2} \frac{E(z)}{1-v^{2}(z)} z d z \quad \text { and } \quad D=\int_{-h / 2}^{h / 2} \frac{E(z)}{1-v^{2}(z)} z^{2} d z
$$

The location $z=0$ in Eq. (17) is at the middle surface of the blister. The axial force and bending moment in the blister are obtained by using Eqs. (6), (7), (15) and (16), which gives

$$
N_{x}=N^{0}-N_{x}^{\mathrm{R}}=A^{*} \varepsilon^{0}-\Delta N^{\mathrm{T}}-A \varepsilon_{x}^{\mathrm{R}}+B \kappa
$$

and

$$
M_{x}=M^{0}-M_{x}^{\mathrm{R}}=B^{*} \varepsilon^{0}-\Delta M^{\mathrm{T}}-B \varepsilon_{x}^{\mathrm{R}}+D \kappa .
$$

Note that stress relaxation only occurs in the blister due to upward bending deflection while the in-plane biaxial compressive residual stress $\sigma^{0}(z)$ in other parts of the multilayer TBC is unchanged.

\subsection{Blister energy}

The key consideration in the PEC-based approach $[12,13]$ is to describe the 'blister energy' $U_{\mathrm{a}}$, which is the net extra energy stored in the growing blister in comparison to the residual strain energy before blister development, $U_{0}$. Note that 'residual' in 'residual strain energy' is used here to mean the strain energy accrued in the top layer after cooling to room temperature due to the mismatch of CTEs, instead of that remaining after fracture has occurred. The blister energy is provided by PECs and is expressed as

$$
U_{\mathrm{a}}=U_{\mathrm{SE}}+U_{\mathrm{s}}-U_{0}
$$

where $U_{\mathrm{SE}}$ is the total strain energy stored in the blister comprising the bending strain energy of the blister due to bending away from the substrate, and the in-plane strain energy of the blister due to the compressive residual stress in the film and stress relaxation in the blister from bending; and $U_{\mathrm{s}}$ is the surface energy of the delaminated surfaces of the blister. By studying the variation of the blister energy $U_{\mathrm{a}}$ with respect to the blister radius, the demand for PECs can be quantified, and furthermore, the blister growth behavior can be characterized.

The sum of the strain energy $U_{\mathrm{SE}}$ is given by 


$$
\begin{aligned}
U_{\mathrm{SE}} & =\frac{b}{2} \int_{-R_{\mathrm{B}}}^{R_{\mathrm{B}}} \int_{-h / 2}^{h / 2}\left\{\begin{array}{l}
{\left[\sigma^{0}(z)-\sigma_{x}^{\mathrm{R}}(z)\right]\left[\varepsilon^{0}(z)-\varepsilon_{x}^{\mathrm{R}}(z)\right]} \\
\left.+\left[\sigma^{0}(z)-\sigma_{y}^{\mathrm{R}}(z)\right]\left[\varepsilon^{0}(z)-\varepsilon_{y}^{\mathrm{R}}(z)\right]\right\} d z d x
\end{array}\right\} \\
& =b \int_{-R_{\mathrm{B}}}^{R_{\mathrm{B}}}\left\{\begin{array}{l}
\frac{A}{2}\left(\varepsilon_{x}^{\mathrm{R}}\right)^{2}-\left(B \kappa+A^{*} \varepsilon^{0}\right) \varepsilon_{x}^{\mathrm{R}}+\left(A^{*}\left(\varepsilon^{0}\right)^{2}+B^{*} \varepsilon^{0} \kappa\right)+\frac{D \kappa^{2}}{2} \\
+\left[\Delta N^{\mathrm{T}}\left(\varepsilon_{x}^{\mathrm{R}}-2 \varepsilon^{0}\right)-\kappa \Delta M^{\mathrm{T}}+2 \Delta u^{\mathrm{T}}\right]
\end{array}\right\} d x \\
& =2 b R_{\mathrm{B}}\left\{\frac{A}{2}\left(\varepsilon_{x}^{\mathrm{R}}\right)^{2}+\left(\frac{D \pi^{2}}{R_{\mathrm{B}}^{2}}-A^{*} \varepsilon^{0}\right) \varepsilon_{x}^{\mathrm{R}}+A^{*}\left(\varepsilon^{0}\right)^{2}+\left[\Delta N^{\mathrm{T}}\left(\varepsilon_{x}^{\mathrm{R}}-2 \varepsilon^{0}\right)+2 \Delta u^{\mathrm{T}}\right]\right\},
\end{aligned}
$$

in which $\Delta u^{\mathrm{T}}$ represents the thermal strain energy density due to $\Delta \varepsilon^{\mathrm{T}}(z)$ in Eq. (3), which is given by

$$
\Delta u^{\mathrm{T}}=\frac{1}{2} \int_{-h / 2}^{h / 2} \frac{E(z)}{1-v(z)}\left[\Delta \varepsilon^{\mathrm{T}}(z)\right]^{2} d z
$$

The surface energy due to the interface fracture $U_{\mathrm{s}}$ in Eq. (20) is

$$
U_{\mathrm{s}}=2 b R_{\mathrm{B}} \bar{G}_{\mathrm{c}},
$$

where $\bar{G}_{\mathrm{c}}$ is the average fracture toughness over the interface. Note that $U_{\mathrm{s}}$ includes both fracture surfaces.

The residual strain energy before delamination $U_{0}$ in Eq. (20) is calculated using Eqs. (5) and (9) as

$$
U_{0}=\frac{b}{2} \int_{-R_{\mathrm{B}}}^{R_{\mathrm{B}}} \int_{-h / 2}^{h / 2}\left[2 \sigma^{0}(z) \varepsilon^{0}(z)\right] d z d x=2 b R_{\mathrm{B}}\left[A^{*}\left(\varepsilon^{0}\right)^{2}-2 \varepsilon^{0} \Delta N^{\mathrm{T}}+2 \Delta u^{\mathrm{T}}\right]
$$

Substituting the energy terms above, along with Eq. (6), into Eq. (20) leads to the blister energy $U_{\mathrm{a}}$ as

$$
U_{\mathrm{a}}=2 b R_{\mathrm{B}}\left\{\frac{A}{2}\left(\varepsilon_{x}^{\mathrm{R}}\right)^{2}+\left(\frac{D \pi^{2}}{R_{\mathrm{B}}^{2}}-N^{0}\right) \varepsilon_{x}^{\mathrm{R}}+\bar{G}_{\mathrm{c}}\right\} .
$$

\subsection{Mixed-mode interface fracture based on classical plate partition theory}

\subsubsection{Nucleation and stable growth}

The task is now to study the interface fracture behavior during blister development by invoking different partition theories [16-21] of energy release rate (ERR) for mixed-mode fracture. The blister grows if the ERR equals or exceeds the interface fracture toughness. The 
measured residual stress at the blister tips in Ref. [14] highlights that the relaxation stress is approximately zero. Therefore, the axial force and bending moment at the blister tip are, respectively,

$$
N_{x \mathrm{~B}}=\left.\left[-\left(N^{0}-N_{x}^{\mathrm{R}}\right)+N^{0}\right]\right|_{x=R_{\mathrm{B}}}=0
$$

and

$$
\begin{aligned}
M_{x \mathrm{~B}} & =\left.\left[-M^{0}+\left(M^{0}-M_{x}^{\mathrm{R}}\right)\right]\right|_{x=R_{\mathrm{B}}}=-M_{x=R_{\mathrm{B}}}^{\mathrm{R}} \\
& =-\left.\left(B \varepsilon_{x}^{\mathrm{R}}-D \kappa\right)\right|_{x=R_{\mathrm{B}}}=\left(-B+\frac{8}{A_{x}} D\right) \varepsilon_{x}^{\mathrm{R}},
\end{aligned}
$$

in which, from Eqs. (11) and (13), the deflection curvature $\kappa$ at the blister tip is

$$
\left.\kappa\right|_{x=R_{\mathrm{B}}}=\left.\frac{d^{2} w}{d x^{2}}\right|_{x=R_{\mathrm{B}}}=\frac{A_{x} \pi^{2}}{2 R_{\mathrm{B}}^{2}}=\frac{8}{A_{x}} \varepsilon_{x}^{R} .
$$

Following from Ref. [18], the total ERR is

$$
G=\frac{A M_{x \mathrm{~B}}^{2}}{2\left(A D-B^{2}\right)} \text {. }
$$

Based on the classical plate partition theory or Euler beam partition theory [16-18], the pure mode-I and mode-II ERRs are

$$
G_{\mathrm{IE}}=\frac{A M_{x \mathrm{~B}}^{2}}{2\left(A D-B^{2}\right)} \quad \text { and } \quad G_{\mathrm{IIE}}=G-G_{\mathrm{IE}}=0
$$

where the subscript 'E' denotes classical plate or Euler beam partition theory. Eqs. (29) and (30) suggest the delamination is pure mode-I fracture, that is, $G_{\mathrm{cE}}=G_{\mathrm{Ic}}$ where the subscript 'c' denotes the critical ERR. The linear fracture propagation criterion is used to determine whether the crack advances $[13,22,23]$, that is, the condition for fracture propagation is

$$
G=G_{\mathrm{c}}=\frac{\psi G_{\mathrm{Ic}}}{\left(G_{\mathrm{I}} / G\right)(\psi-1)+1},
$$

where $\psi=G_{\text {IIc }} / G_{\text {Ic }}$.

Substituting Eqs. (29) and (30) into Eq. (31), and using Eqs. (13) and (27), leads to 


$$
A_{x}^{2}\left[1-\frac{B A_{x}}{8 D}\right]^{2}=\frac{\left(A D-B^{2}\right)}{A D} \frac{8 G_{\mathrm{cE}}}{\pi^{4} D} R_{\mathrm{B}}^{4}
$$

According to classical laminate theory, $\left(A D-B^{2}\right)$ is always positive. This also satisfies the requirement for ERR in Eq. (29) to be positive. Then, $A_{x}$ is obtained from Eq. (32) as

$$
\left(A_{x}\right)_{\mathrm{GRE}}=\frac{4 D}{B}\left[1-\left(1-R_{\mathrm{B}}^{2} \frac{2 B}{D \pi^{2}} \sqrt{\frac{G_{\mathrm{cE}} \xi}{D}}\right)^{1 / 2}\right],
$$

where $\xi=\left(A D-B^{2}\right) /(2 A D)$ and the subscript 'GR' denotes a quantity during growth. For a multilayer TBC, $\xi \leq 1 / 2$, and for an isotropic blister layer, $\xi=1 / 2$. Furthermore, it is easily shown that the second term inside the square brackets of Eq. (32) is generally much smaller than 1 and negligible. The corresponding $A_{x}$ is

$$
\left(A_{x}^{2}\right)_{\mathrm{GRE}}=\xi \frac{16 G_{\mathrm{cE}}}{\pi^{4} D}\left(R_{\mathrm{B}}^{4}\right)_{\mathrm{GRE}} .
$$

The mid-surface relaxation strain during growth is obtained by substituting Eq. (34) into Eq. (13), giving

$$
\left(\varepsilon_{x}^{\mathrm{R}}\right)_{\mathrm{GRE}}=\xi \frac{G_{\mathrm{cE}}\left(R_{\mathrm{B}}^{2}\right)_{\mathrm{GRE}}}{\pi^{2} D} .
$$

Then, the blister energy during growth is then obtained by substituting Eq. (35) into Eq. (25), and noting that $\bar{G}_{\mathrm{c}}=G_{\mathrm{cE}}$, as shown by Eqs. (30) and (31), giving

$$
\left(U_{\mathrm{a}}\right)_{\mathrm{GRE}}=2 b\left(R_{\mathrm{B}}\right)_{\mathrm{GRE}}\left\{\frac{A}{2}\left(\frac{\xi G_{\mathrm{cE}}}{\pi^{2} D}\right)^{2}\left(R_{\mathrm{B}}^{4}\right)_{\mathrm{GRE}}-N^{0} \frac{\xi G_{\mathrm{cE}}}{\pi^{2} D}\left(R_{\mathrm{B}}^{2}\right)_{\mathrm{GRE}}+G_{\mathrm{cE}}(1+\xi)\right\} .
$$

Note that $\left(U_{\mathrm{a}}\right)_{\mathrm{GRE}}$ in Eq. (36) is for delamination on the TGO/BC interface only without any consideration for ridge cracks. It will, however, be seen in Section 4.2 that the developed mechanical model can still give good agreement with test results even if ridge cracks appear. This is may be because the surface energy associated with ridge-cracks is generally small due to the relatively small crack area in comparison to that associated with delamination. Moreover, since ridge cracks 'consume' a small amount of blister energy, the measured spallation radius is expected to be slightly smaller than the predicted one, which will be observed in Section 4.2.

During blister nucleation, $R_{\mathrm{B}}$ is very small and the higher-order $R_{\mathrm{B}}$ terms in Eq. (36) can be neglected, giving 


$$
\left(U_{\mathrm{a}}\right)_{\mathrm{NUE}}=2 b\left(R_{\mathrm{B}}\right)_{\mathrm{NUE}} G_{\mathrm{cE}}(1+\xi),
$$

where 'NU' denotes the nucleation of a blister. This is the blister nucleation energy, which must be supplied by some energy source if a blister is to nucleate. According to the PECs hypothesis, this energy source is PECs.

Eq. (37) shows that the blister nucleation energy solely depends on the mechanical properties, namely, interface fracture toughness, Young's modulus and Poisson's ratio, and their through-thickness variations. Taking EBPVD TBCs as an example, the TC has a dense layer near to the TGO, a coarse layer near to the TC surface, and sintering on the TC surface. Since $\xi \leq 1 / 2$ for a multilayer TBC, as shown above, then $(1+\xi)$ in Eq. (37) has a maximum value of 1.5, which is when the bending-stretching coupling stiffness $B$ is zero. TGO growth increases the value of $B$ and thus decreases the nucleation energy.

\subsubsection{Initiation of unstable growth}

After nucleation, a blister initially grows steadily and slowly, with PECs supplying the required energy for blister growth, as described by Eq. (36). If the required energy is not available, then the blister cannot grow further and stalls. Assuming a sufficient supply of energy for continued blister growth, then when the blister width reaches a certain critical value, the blister then grows unstably. Following Refs. [12,13] for a monolayer film, based on the buckling condition of a thin plate, the condition for unstable growth of a straight blister is

$$
N^{0}-\bar{N}_{x}^{\mathrm{R}}=\frac{(\alpha \pi)^{2} D}{R_{\mathrm{B}}^{2}},
$$

where, from Eqs. (15) and (11), $\bar{N}_{x}^{\mathrm{R}}=\int_{0}^{R_{\mathrm{B}}} N_{x}^{\mathrm{R}} d x / R_{\mathrm{B}}=A\left(\varepsilon_{x}^{\mathrm{R}}\right)_{\mathrm{GRE}}$, which represents the average axial relaxation force. The range of $\alpha$ is $0.5 \leq \alpha \leq 1.0$ and the two limits correspond to the simply-supported and clamped edge conditions respectively. Refs. [12,13] have demonstrated that $\alpha=0.75$ is a good approximation for a single layer blister with a brittle interface.

The blister half-width for the initiation of unstable growth $\left(R_{\mathrm{B}}\right)_{\mathrm{UGE}}$ can be obtained from the following by combining Eqs. (35) and (38) as

$$
\left(R_{\mathrm{B}}^{2}\right)_{\mathrm{UGE}}=\frac{\pi^{2} D \varphi_{\mathrm{E}}^{0}}{2 \xi A}\left[1-\left(1-\frac{2 \alpha^{2} \xi}{\Omega_{\mathrm{E}}}\right)^{1 / 2}\right],
$$

where 'UG' denotes the unstable growth of the blister, and 


$$
\Omega_{\mathrm{E}}=\frac{N^{0}}{2 A} \varphi_{\mathrm{E}}^{0}=\frac{\left(N^{0}\right)^{2}}{2 A G_{\mathrm{cE}}} \quad \text { and } \quad \varphi_{\mathrm{E}}^{0}=\frac{N^{0}}{G_{\mathrm{cE}}} .
$$

Note that $\Omega$ represents the ratio between the in-plane strain energy per unit width and the interface adhesion toughness. The $\Omega$ ratio plays a key role in blister development.

From Eq. (39), unstable growth only occurs if $\Omega_{\mathrm{E}} \geq 2 \alpha^{2} \xi$. Since $\xi \leq 1 / 2$, the maximum possible value of $2 \alpha^{2} \xi$ is $\alpha^{2}$, which is for an isotropic blister. TGO growth and TC sintering make $\Delta \varepsilon^{\mathrm{T}}(z)$ in Eq. (3) increasingly negative, and consequently increase $\Omega_{\mathrm{E}}$ by increasing $N^{0}$ in Eq. (6). Furthermore, they simultaneously decrease $2 \alpha^{2} \xi$ because of the increased stretching-bending coupling of the TBC. When $\Omega_{\mathrm{E}} \square 2 \alpha^{2} \xi$, binomial expansion of the square brackets in Eq. (39) leads to

$$
\left(R_{\mathrm{B}}^{2}\right)_{\mathrm{UGE}}=\frac{(\alpha \pi)^{2} D}{N^{0}} .
$$

This reveals that TGO growth and TC sintering promote unstable growth by increasing the residual loads and decreasing $\left(R_{\mathrm{B}}^{2}\right)_{\mathrm{UGE}}$ in Eq. (41). Note that for uniform material properties through the blister thickness, Eq. (41) reduces to the same form given in Refs. [12,13].

When $\Omega_{\mathrm{E}} \square 2 \alpha^{2} \xi$, the blister height, mid-surface relaxation strain and the blister energy at the initiation of unstable growth are derived by substituting Eq. (41) into Eqs. (34), (35) and (36) respectively, giving

$$
\begin{gathered}
\left(A_{x}^{2}\right)_{\mathrm{UGE}}=\frac{8 \xi D \alpha^{4}}{A \Omega_{\mathrm{E}}}, \\
\left(\varepsilon_{x}^{\mathrm{R}}\right)_{\mathrm{UGE}}=\frac{\xi \alpha^{2}}{\varphi_{\mathrm{E}}^{0}}
\end{gathered}
$$

and

$$
\begin{aligned}
\left(U_{\mathrm{a}}\right)_{\mathrm{UGE}} & =2 b\left(R_{\mathrm{B}}\right)_{\mathrm{UGE}} G_{\mathrm{cE}}\left[\frac{\xi^{2} \alpha^{4}}{4 \Omega_{\mathrm{E}}}+\xi\left(1-\alpha^{2}\right)+1\right] \\
& \approx 2 b\left(R_{\mathrm{B}}\right)_{\mathrm{UGE}} G_{\mathrm{cE}}\left[\xi\left(1-\alpha^{2}\right)+1\right] .
\end{aligned}
$$

\subsubsection{Maximum blister energy and unstable growth}

Based on Eq. (36), the blister energy reaches its maximum value at 


$$
\left(R_{\mathrm{B}}^{2}\right)_{\mathrm{MUE}}=\frac{3 D \pi^{2} \varphi_{\mathrm{E}}^{0}}{5 \xi A}\left[1-\left(1-\frac{5(1+\xi)}{9 \Omega_{\mathrm{E}}}\right)^{1 / 2}\right]
$$

where 'MU' denotes the maximum blister energy. Note that $\left(R_{\mathrm{B}}^{2}\right)_{\mathrm{MUE}}$ exists only if $\Omega_{\mathrm{E}} \geq 5(1+\xi) / 9$. The maximum possible value of $5(1+\xi) / 9$ is $5 / 6$, which is for an isotropic blister with $\xi=1 / 2$. Without considering other effects such as creep or plastic relaxation, TGO growth and TC sintering act to increase $\Omega_{\mathrm{E}}$ by increasing $N^{0}$ in Eq. (6), and simultaneously decrease $5(1+\xi) / 9$. When $\Omega_{\mathrm{E}} \square 5(1+\xi) / 9$, binomial expansion of the square brackets in Eq. (45) leads to

$$
\left(R_{\mathrm{B}}^{2}\right)_{\mathrm{MUE}}=\frac{(1+\xi) \pi^{2} D}{3 N^{0} \xi}
$$

When $\Omega_{\mathrm{E}} \square 5(1+\xi) / 9$, the blister height, mid-surface relaxation strain and the blister energy are obtained by substituting Eq. (46) into Eqs. (34), (35) and (36) respectively, giving

$$
\begin{gathered}
\left(A_{x}^{2}\right)_{\mathrm{MUE}}=\frac{8 D(1+\xi)^{2}}{9 A \Omega_{\mathrm{E}} \xi}, \\
\left(\varepsilon_{x}^{\mathrm{R}}\right)_{\mathrm{MUE}}=\frac{(1+\xi)}{3 \varphi_{\mathrm{E}}^{0}}
\end{gathered}
$$

and

$$
\left(U_{\mathrm{a}}\right)_{\mathrm{MUE}}=2 b\left(R_{\mathrm{B}}\right)_{\mathrm{MUE}} G_{\mathrm{cE}}\left\{\frac{(1+\xi)^{2}}{36 \Omega_{\mathrm{E}}}+\frac{2(1+\xi)}{3}\right\} \approx \frac{4}{3} b\left(R_{\mathrm{B}}\right)_{\mathrm{MUE}} G_{\mathrm{cE}}(1+\xi) .
$$

Since the maximum blister energy radius $\left(R_{\mathrm{B}}\right)_{\mathrm{MUE}}$ in Eq. (46) is greater than unstable growth radius $\left(R_{\mathrm{B}}\right)_{\mathrm{UGE}}$ in Eq. (39), after the initiation of unstable growth, the blister energy continues to increase up to the blister energy capacity $\left(U_{\mathrm{a}}\right)_{\mathrm{MUE}}$. Since the blister energy $U_{\mathrm{a}}$ is increasing up to this point, an energy source is still required despite the growth being unstable. As before, according to the hypothesis of PECs, PECs are the energy source that supplies this blister energy. If PECs cannot provide the required energy, then the blister cannot grow further and stalls. 


\subsubsection{Spallation}

After the blister energy has reached its maximum value of $\left(U_{\mathrm{a}}\right)_{\mathrm{MUE}}$, it then decreases with further blister growth, and no more energy is needed from PECs. The blister now has enough energy stored in itself to continue propagating, and it is therefore both fast and unstable as the blister energy is converted into kinetic energy. If the blister energy reduces to zero and the kinetic energy of the blister due to the fast unstable growth is large enough to break the blister edges, then the blister will spall off from the substrate. From Eq. (36), the blister half-width at spallation $\left(R_{\mathrm{B}}\right)_{\mathrm{SPE}}$ is obtained from

$$
\left(R_{\mathrm{B}}^{2}\right)_{\mathrm{SPE}}=\frac{D \pi^{2} \varphi_{\mathrm{E}}^{0}}{\xi A}\left[1-\left(1-\frac{(1+\xi)}{\Omega_{\mathrm{E}}}\right)^{1 / 2}\right]
$$

Note that the negative square root in Eq. (50) is chosen to get the smaller value of $\left(R_{\mathrm{B}}^{2}\right)_{\mathrm{SPE}}$. It is seen that no solutions for $\left(R_{\mathrm{B}}^{2}\right)_{\mathrm{SPE}}$ exist if $\Omega_{\mathrm{E}}<(1+\xi)$, and so spallation cannot occur if this condition is satisfied. When $\Omega_{\mathrm{E}} \square(1+\xi)$, binomial expansion of the square brackets in Eq. (50) leads to

$$
\left(R_{\mathrm{B}}^{2}\right)_{\mathrm{SPE}}=\frac{\pi^{2} D(1+\xi)}{\xi N^{0}} .
$$

When $\Omega_{\mathrm{E}} \square(1+\xi)$, the blister height and mid-surface relaxation strain are obtained by substituting Eq. (46) into Eqs. (34) and (35) respectively, giving

$$
\left(A_{x}^{2}\right)_{\mathrm{SPE}}=\frac{8 D(1+\xi)^{2}}{A \xi \Omega_{\mathrm{E}}}
$$

and

$$
\left(\varepsilon_{x}^{\mathrm{R}}\right)_{\mathrm{SPE}}=\varphi_{\mathrm{E}}^{0}(1+\xi)
$$

Two conditions are derived in the above for the spallation of TBCs to occur: (1) From Eq. (49), PECs must be able to supply sufficient energy to take the blister energy to $\left(U_{\mathrm{a}}\right)_{\mathrm{MUE}}$. After this point, the blister has stored enough energy in itself to continue propagating with no further energy requirement. (2) From Eq. (50), $\Omega_{\mathrm{E}}$ must be $\Omega_{\mathrm{E}} \geq(1+\xi)$. These two conditions provide valuable guidance for TBC design and optimisation to avoid spallation failure. 
Condition 1 partly relates to the prevalence of PECs and the availability of energy for blister development, but this depends on the precise cause of PECs, which is beyond the scope of this work. The maximum blister energy $\left(U_{\mathrm{a}}\right)_{\mathrm{MUE}}$, however, can be increased to delay condition 1 being satisfied. From Eqs. (46) and (49), this could be achieved by decreasing $N^{0}$-by decreasing $\varepsilon^{0}$ or by increasing $N^{\mathrm{T}}$ via $\Delta \varepsilon^{\mathrm{T}}(z)$ as per Eq. (6)—or by increasing $G_{\mathrm{cE}}$. Note that $\xi$ has a limited range so has a relatively minor effect. Condition 2 requires decreasing $\Omega_{\mathrm{E}}$ , which, as the ratio of in-plane strain energy density per unit width to interface adhesion toughness, could be achieved in the same ways as for condition 1 .

Practically, increased lifetime of EBPVD TBCs could therefore be achieved by: (1) Reducing the thickness of the dense-layer at the bottom of the TC. (2) Reducing the growth rate of the TGO. (3) Suppressing TC sintering. (4) Reducing the temperature difference across the coating. (5) Reducing mismatch of CTEs between the blister and the BC.

\subsection{Mixed-mode interface fracture based on first-order shear-deformable plate partition theory and 2D elasticity partition theory}

The mixity of a mixed-mode interface fracture depends on the partition theory. In this section, the PEC-based mechanical model developed in Section 2.4 using classical plate partition theory is adjusted for first-order shear-deformable plate partition theory (or equivalently, Timoshenko beam partition theory) $[16,17,22-24]$ and for $2 \mathrm{D}$ elasticity partition theory $[19,20,22,25]$. The parameters $G_{\mathrm{cE}}, \Omega_{\mathrm{E}}$ and $\varphi_{E}^{0}$ in the above need to be replaced by $G_{\mathrm{cT}}$ , $\Omega_{\mathrm{T}}$, and $\varphi_{\mathrm{T}}^{0}$ respectively for first-order shear-deformable plate partition theory, and by $G_{\mathrm{c} 2 \mathrm{D}}$ , $\Omega_{2 \mathrm{D}}$ and $\varphi_{2 \mathrm{D}}^{0}$ respectively $2 \mathrm{D}$ elasticity partition theory.

The ERRs based on first-order shear-deformable plate partition theory are

$$
G_{\mathrm{IT}}=\frac{2 M_{x \mathrm{~B}}^{2}}{\left(A h^{2}+4 B h+4 D\right)} \quad \text { and } \quad G_{\mathrm{IIT}}=G-G_{\mathrm{IT}}
$$

From Eqs. (29) and (54), the fracture mode mixity is constant at $G_{\text {IT }} / G=4\left(A D-B^{2}\right) /\left[A\left(A h^{2}+4 B h+4 D\right)\right]=1 / \psi_{\text {IT }}$. Substituting $G_{\text {IT }} / G=1 / \psi_{\text {IT }} \quad$ into Eq. (31) gives

$$
\lambda_{\mathrm{T}}=\frac{G_{\mathrm{cT}}}{G_{\mathrm{Ic}}}=\frac{\psi \psi_{\mathrm{IT}}}{\psi+\psi_{\mathrm{IT}}-1} .
$$


Therefore the relationship between the critical ERR from first-order plate partition theory and that from classical plate partition theory is

$$
G_{\mathrm{cT}}=\lambda_{\mathrm{T}} G_{\mathrm{Ic}}=\lambda_{\mathrm{T}} G_{\mathrm{cE}}
$$

Now $\Omega_{\mathrm{T}}$ and $\varphi_{\mathrm{T}}^{0}$ are obtained by substituting Eq. (56) into Eq. (40), giving

$$
\Omega_{\mathrm{T}}=\frac{N^{0}}{2 A} \varphi_{\mathrm{T}}^{0}=\frac{\left(N^{0}\right)^{2}}{2 A G_{\mathrm{cT}}}=\frac{\Omega_{\mathrm{E}}}{\lambda_{\mathrm{T}}} \quad \text { and } \quad \varphi_{\mathrm{T}}^{0}=\frac{N^{0}}{G_{\mathrm{cT}}} .
$$

Similarly, the ERRs based on 2D elasticity partition theory are

$$
G_{\mathrm{I} 2 \mathrm{D}}=0.6227 \frac{6 M_{x \mathrm{~B}}^{2}}{A h^{2}} \quad \text { and } \quad G_{\mathrm{II} 2 \mathrm{D}}=G-G_{\mathrm{I} 2 \mathrm{D}}
$$

The fracture mode mixity is constant at $G_{\mathrm{I} 2 \mathrm{D}} / G_{2 \mathrm{D}}=0.6227\left[12\left(A D-B^{2}\right) /\left(A^{2} h^{2}\right)\right]=1 / \psi_{\mathrm{I} 2 \mathrm{D}}$. The quantities $G_{\mathrm{c} 2 \mathrm{D}}, \Omega_{2 \mathrm{D}}$ and $\varphi_{2 \mathrm{D}}^{0}$ are determined in the same way as above, with $\lambda_{2 \mathrm{D}}$ obtained by replacing $\psi_{\mathrm{IT}}$ with $\psi_{\mathrm{I} 2 \mathrm{D}}$ in Eq. (55), giving

$$
\begin{gathered}
G_{\mathrm{c} 2 \mathrm{D}}=\lambda_{2 \mathrm{D}} G_{\mathrm{Ic}}=\lambda_{2 \mathrm{D}} G_{\mathrm{cE}}, \\
\Omega_{2 D}=\frac{N^{0}}{2 A} \varphi_{2 \mathrm{D}}^{0}=\frac{\left(N^{0}\right)^{2}}{2 A G_{\mathrm{c} 2 \mathrm{D}}}=\frac{\Omega_{\mathrm{E}}}{\lambda_{2 \mathrm{D}}} \text { and } \varphi_{2 \mathrm{D}}^{0}=\frac{N^{0}}{G_{\mathrm{c} 2 \mathrm{D}}} .
\end{gathered}
$$

\section{PEC-based mechanical model for circular blisters in multilayer TBCs}

The PEC-based mechanical model for the circular blisters is similar to the model for straight blisters, described in Section 2; therefore, only the key differences are recorded in this section. Figure 2 shows a multilayer circular blister of diameter $2 R_{\mathrm{B}}$, blister thickness $h$, and height $A_{r}$. The model is developed in polar coordinates, and so the $x$ coordinate in Section 2 is swapped to the $r$ coordinate where appropriate. 


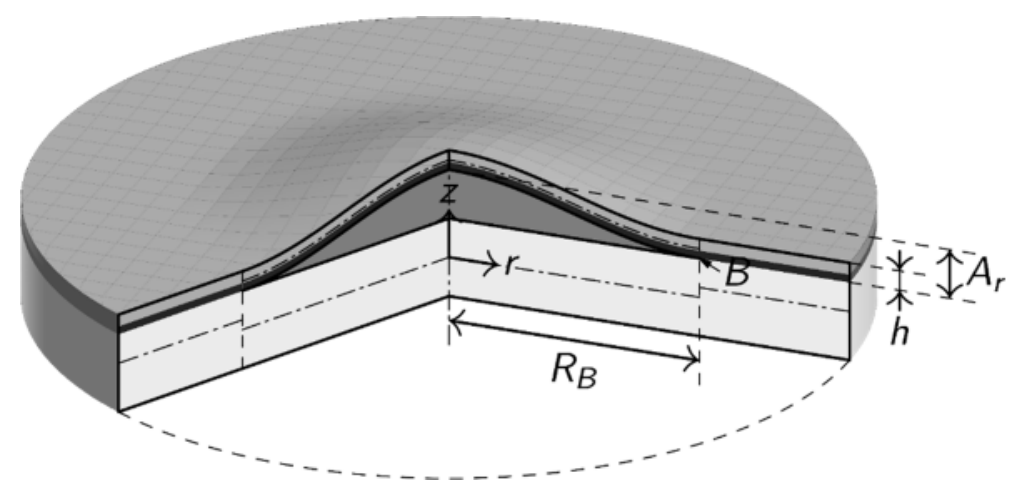

Figure 2 A circular coating blister.

The circular blister shape is assumed to be axisymmetric and sinusoidal $[12,13]$, obeying

$$
w(r)=\frac{A_{r}}{2}\left[1+\cos \left(\frac{\pi r}{R_{\mathrm{B}}}\right)\right]
$$

Based on the assumed blister shape, the blister energy is

$$
U_{\mathrm{a}}=\pi R_{\mathrm{B}}^{2}\left\{\frac{A}{2}\left(\varepsilon_{x}^{\mathrm{R}}\right)^{2}+\left(\frac{D \pi^{2}}{R_{\mathrm{B}}^{2}}-N^{0}\right) \varepsilon_{x}^{\mathrm{R}}+\bar{G}_{\mathrm{c}}\right\} .
$$

Note the similarity between the blister energy in Eq. (62) for circular blisters and that for straight blisters in Eq. (25).

The total ERR and its mixity for a circular blister, based on classical plate partition theory [16-18], are identical to those for straight blisters, as given in Eqs. (29) and (30) respectively. The linear fracture propagation criterion in Eq. (31) is still used to determine crack propagation. There are no changes to $\left(A_{r}\right)_{\mathrm{GRE}}$ and $\left(\varepsilon_{r}^{\mathrm{R}}\right)_{\mathrm{GRE}}$, as given in Eqs (34) and (35) respectively. Based on these expressions, the blister energy of a circular blister during growth is

$$
\left(U_{\mathrm{a}}\right)_{\mathrm{GRE}}=\pi\left(R_{\mathrm{B}}^{2}\right)_{\mathrm{GRE}}\left\{\frac{A}{2}\left(\frac{\xi G_{\mathrm{cE}}}{\pi^{2} D}\right)^{2}\left(R_{\mathrm{B}}^{4}\right)_{\mathrm{GRE}}-N^{0} \frac{\xi G_{\mathrm{cE}}}{\pi^{2} D}\left(R_{\mathrm{B}}^{2}\right)_{\mathrm{GRE}}+G_{\mathrm{cE}}(1+\xi)\right\},
$$

and the nucleation energy is

$$
\left(U_{\mathrm{a}}\right)_{\mathrm{NUE}}=\pi\left(R_{\mathrm{B}}^{2}\right)_{\mathrm{NUE}} G_{\mathrm{cE}}(1+\xi)
$$

For the initiation of unstable growth of a circular blister, there are no changes to $\left(R_{\mathrm{B}}\right)_{\mathrm{UGE}}$, $\left(A_{r}\right)_{\mathrm{UGE}}$ and $\left(\varepsilon_{r}^{\mathrm{R}}\right)_{\mathrm{UGE}}$, as given in Eqs. (39), and (41) to (43) respectively. Note, however, that the range of $\alpha$ now becomes $0.652 \leq \alpha \leq 1.220$ where the two limits correspond to the simply- 
supported and clamped edge conditions respectively. It has been shown that $\alpha=0.936$ is a good approximation [12,13]. Based on these expressions together with Eq. (63), the blister energy of a circular blister at the initiation of unstable growth if $\Omega_{\mathrm{E}} \square 2 \alpha^{2} \xi$ is

$$
\begin{aligned}
\left(U_{\mathrm{a}}\right)_{\mathrm{UGE}} & =\pi\left(R_{\mathrm{B}}^{2}\right)_{\mathrm{UGE}} G_{\mathrm{cE}}\left[\frac{\xi^{2} \alpha^{4}}{4 \Omega_{E}}+\xi\left(1-\alpha^{2}\right)+1\right] \\
& \approx \pi\left(R_{\mathrm{B}}^{2}\right)_{\mathrm{UGE}} G_{\mathrm{cE}}\left[\xi\left(1-\alpha^{2}\right)+1\right] .
\end{aligned}
$$

The blister energy of a circular blister reaches its maximum value at

$$
\left(R_{\mathrm{B}}^{2}\right)_{\mathrm{MUE}}=\frac{2 D \pi^{2} \varphi_{\mathrm{E}}^{0}}{3 \xi A}\left[1-\left(1-\frac{3(1+\xi)}{4 \Omega_{\mathrm{E}}}\right)^{1 / 2}\right] .
$$

There are no solutions for $\left(R_{\mathrm{B}}^{2}\right)_{\mathrm{MUE}}$ if $\Omega_{\mathrm{E}}<3(1+\xi) / 4$. When $\Omega_{\mathrm{E}} \square 3(1+\xi) / 4$, binomial expansion of the square brackets in Eq. (66) leads to

$$
\left(R_{\mathrm{B}}^{2}\right)_{\mathrm{MUE}}=\frac{D \pi^{2}(1+\xi)}{2 \xi N^{0}} .
$$

The blister height, mid-surface axial relaxation strain and the maximum blister energy are obtained by substituting Eq. (67) into Eqs. (34), (35) and (36) respectively, giving

$$
\begin{gathered}
\left(A_{x}^{2}\right)_{\mathrm{MUE}}=\frac{2 D(1+\xi)^{2}}{A \xi \Omega_{\mathrm{E}}}, \\
\left(\varepsilon_{x}^{\mathrm{R}}\right)_{\mathrm{MUE}}=\frac{(1+\xi)}{2 \varphi_{\mathrm{E}}^{0}}
\end{gathered}
$$

and

$$
\left(U_{\mathrm{a}}\right)_{\mathrm{MUE}}=\pi\left(R_{\mathrm{B}}^{2}\right)_{\mathrm{MUE}} G_{\mathrm{cE}}\left\{\frac{(1+\xi)^{2}}{16 \Omega_{\mathrm{E}}}+\frac{(1+\xi)}{2}\right\} \approx \frac{1}{2} \pi\left(R_{\mathrm{B}}^{2}\right)_{\mathrm{MUE}} G_{\mathrm{cE}}(1+\xi) .
$$

For the spallation of a circular blister, there are no changes to Eqs. (50) to (53). The mechanical model given above, based on classical plate partition theory, can also be adjusted for first-order shear-deformable plate partition theory and for 2D elasticity partition theory by changing the relevant parameters, as described in Section 2.5. There is no change to those parameters for circular blisters. 


\section{Experimental validation}

In this section, the developed PEC-based mechanical model for multilayer material systems is verified first against radius measurements of alumina scale spallation [26], and then against radius measurements of EBPVD TBC spallation [27]. Note that all spallation happens having reached room temperature, that is, under constant biaxial compressive residual stress.

\subsection{Alumina scale spallation}

The relevant experimental details of the alumina spallation tests are recorded here from Refs. [26]. The specimens were $25.4 \mathrm{~mm}$ diameter discs of commercial FeCrAlY alloy (Fe$22 \mathrm{Cr}-5 \mathrm{Al}-0.1 \mathrm{Y}-0.3 \mathrm{Si}-0.2 \mathrm{Mn}-0.1 \mathrm{Zr}-0.02 \mathrm{C}$ in $\mathrm{wt} \%$ ), with thicknesses of $0.477 \mathrm{~mm}$, $1.394 \mathrm{~mm}, 3.349 \mathrm{~mm}$ and $7.608 \mathrm{~mm}$, polished to a $0.25-\mu \mathrm{m}$ finish on both sides. The specimens were oxidized in a chamber furnace at the isothermal temperature of $1200^{\circ} \mathrm{C}$, following heating at $3{ }^{\circ} \mathrm{C} \mathrm{min}{ }^{-1}$, to produce a uniform flat alumina scale, adhered to the substrate surface. The $4.5 \mu \mathrm{m}$-thick alumina films were generated after being oxidized for $25 \mathrm{~h}$, and the specimens were cooled to room temperature at various cooling rates $(1,5,10,30$ and $100{ }^{\circ} \mathrm{C} \mathrm{min}-1$ ), as indicated in Table 1. Compressive residual stress was generated in the scale during cooling and became constant upon reaching room temperature. The residual stress in the scale was measured using photo-stimulated luminescence spectroscopy, and the values for each group are additionally recoded in Table 1. The spallation behavior of the alumina layer was monitored using an optical microscope as well as scanning electron microscopy (SEM). When the cooling rate was 1 or $100^{\circ} \mathrm{C} \mathrm{min}-1$, spallation was not observed but blisters were evident. For the intermediate cooling rates of 5,10 and $30{ }^{\circ} \mathrm{C} \mathrm{min}^{-1}$, spallation occurred significantly. 
Table 1 Values of $\Omega$ based on the E, T and 2D partition theories for different experimental samples.

\begin{tabular}{|c|c|c|c|c|c|}
\hline \multirow{2}{*}{ Cooling rate, substrate thickness } & \multirow{2}{*}{$\begin{array}{c}h \\
(\mu \mathrm{m})\end{array}$} & \multirow{2}{*}{$\begin{array}{c}\sigma_{0} \\
(\mathrm{GPa})\end{array}$} & \multicolumn{3}{|c|}{$\Omega$} \\
\hline & & & $\mathrm{E}$ & $\mathrm{T}$ & $2 \mathrm{D}$ \\
\hline $30{ }^{\circ} \mathrm{C} \mathrm{min}{ }^{-1}, 0.477 \mathrm{~mm}$ & 4.5 & 3.023 & 5.6037 & 2.2415 & 3.9123 \\
\hline $30{ }^{\circ} \mathrm{C} \mathrm{min}{ }^{-1}, 1.394 \mathrm{~mm}$ & 4.5 & 4.142 & 10.5200 & 4.2080 & 7.3448 \\
\hline $10^{\circ} \mathrm{C} \min ^{-1}, 1.394 \mathrm{~mm}$ & 4.5 & 3.845 & 9.0654 & 3.6262 & 6.3293 \\
\hline $5^{\circ} \mathrm{C} \mathrm{min} \min ^{-1}, 1.394 \mathrm{~mm}$ & 4.5 & 3.759 & 8.6644 & 3.4658 & 6.0493 \\
\hline $30^{\circ} \mathrm{C} \mathrm{min}^{-1}, 3.349 \mathrm{~mm}$ & 4.5 & 4.468 & 12.2411 & 4.8965 & 8.5465 \\
\hline $30{ }^{\circ} \mathrm{C} \mathrm{min}^{-1}, 7.608 \mathrm{~mm}$ & 4.5 & 4.947 & 15.0065 & 6.0026 & 10.4772 \\
\hline
\end{tabular}

The Young's modulus of the alumina scale is $E_{\mathrm{TGO}}=400 \mathrm{GPa}$ and the Poisson's ratio is $v_{\mathrm{TGO}}=0.25[7,28]$. The mode-I fracture toughness of the interface between the scale and the substrate is $G_{\mathrm{Ic}}=8.6 \mathrm{~J} \mathrm{~m}^{-2}$ [4] and the fracture toughness ratio $\psi$ is 5 [29]. Since the alumina scale is isotropic, $\Delta \varepsilon^{\mathrm{T}}(z)$ in Eq. (3) equals zero, and the fracture toughness $G_{\mathrm{c}}$, based on classical plate partition theory, first-order shear-deformable plate partition theory, and 2D elasticity partition theory, is calculated as $8.60 \mathrm{~J} \mathrm{~m}^{-2}, 21.50 \mathrm{~J} \mathrm{~m}^{-2}$ and $12.32 \mathrm{~J} \mathrm{~m}^{-2}$ respectively. The values of $\Omega$ for the various samples are calculated and summarized in Table 1 . It is seen that all values of $\Omega$ are more than $3 / 2$ which is required by Eq. (51). Using the mechanical model for circular blisters with $\alpha=0.936$, the radii for initiation of unstable growth and spallation are predicted and compared with experimental measurements in Table $\mathbf{2}$, where ' $\mathrm{E}$ ', ' $\mathrm{T}$ ' and '2D' denote classical plate partition theory, first-order shear-deformable plate partition theory, and 2D elasticity partition theory respectively. Note that the blisters were "circular" or "near-circular" [26] and the average diameter was measured based on ten random images from each sample.

From Table 2, it is seen that spallation radii predicted by the mechanical model using each of the three partition theories are all in excellent agreement with the experimental measurements. Since $\Omega \square 3 / 2$, the approximate Eqs. (41) and (51) are appropriate and also work very well. No radius measurements at the initiation of unstable growth are available. Overall, the accuracy of the mechanical model in predicting spallation radius provides strong support for the hypothesis that spallation is driven by both PECs and buckling. 
Table 2 Radii for initiation of unstable growth and spallation and comparisons with experimental measurements (spallation only).

\begin{tabular}{|c|c|c|c|c|c|c|c|c|c|}
\hline \multirow{3}{*}{$\begin{array}{l}\text { Cooling rate, } \\
\text { substrate } \\
\text { thickness }\end{array}$} & \multicolumn{4}{|c|}{$\begin{array}{l}R_{\mathrm{B}} \text { at initiation of unstable } \\
\text { growth }(\mu \mathrm{m})\end{array}$} & \multicolumn{5}{|c|}{$R_{\mathrm{B}}$ at spallation $(\mu \mathrm{m})$} \\
\hline & \multicolumn{3}{|c|}{ Eq. (39) } & \multirow{2}{*}{$\begin{array}{c}\text { Eq. (41) } \\
\text { All }\end{array}$} & \multicolumn{3}{|c|}{ Eq. (50) } & \multicolumn{2}{|l|}{ Eq. (51) } \\
\hline & $\mathrm{E}$ & $\mathrm{T}$ & $2 \mathrm{D}$ & & $\mathrm{E}$ & $\mathrm{T}$ & $2 \mathrm{D}$ & All & Test data \\
\hline $\begin{array}{c}30^{\circ} \mathrm{C} \mathrm{min}^{-1} \\
0.477 \mathrm{~mm}\end{array}$ & 46.33 & 48.10 & 46.80 & 45.38 & 87.18 & 94.63 & 88.88 & 83.98 & $89.70 \pm 4.00$ \\
\hline 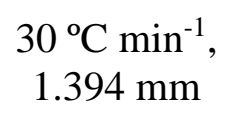 & 39.19 & 39.88 & 39.38 & 38.77 & 73.11 & 75.58 & 73.76 & 71.74 & $74.29 \pm 4.00$ \\
\hline 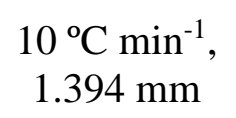 & 40.75 & 41.60 & 40.98 & 40.24 & 76.12 & 79.25 & 76.93 & 74.46 & $76.60 \pm 4.00$ \\
\hline $\begin{array}{l}5^{\circ} \mathrm{C} \mathrm{min}-1 \\
1.394 \mathrm{~mm}\end{array}$ & 41.23 & 42.15 & 41.48 & 40.70 & 77.08 & 80.44 & 77.94 & 75.31 & $76.60 \pm 4.00$ \\
\hline $\begin{array}{c}30{ }^{\circ} \mathrm{C} \mathrm{m^{-1 }}, \\
3.349 \mathrm{~mm}\end{array}$ & 37.67 & 38.24 & 37.83 & 37.33 & 70.19 & 72.16 & 70.72 & 69.07 & $71.66 \pm 4.00$ \\
\hline $\begin{array}{l}30^{\circ} \mathrm{C} \min ^{-1} \\
7.608 \mathrm{~mm}\end{array}$ & 35.74 & 36.17 & 35.86 & 35.47 & 66.5 & 67.96 & 66.9 & 65.65 & $67.20 \pm 4.00$ \\
\hline
\end{tabular}

Although it is not the objective of this work to determine the origin of PECs, the experimental observations presented in Refs. [26] suggest the following possible sources of PECs in the case of these FeCrAlY alloy/alumina tests: (1) Imprints of alumina grains on the substrate, which make rough and wrinkled interfaces; (2) dislocations of grain boundaries at interfaces; (3) plastic deformation; and (4) Chromium carbide segregation.

\subsection{EBPVD coating spallation}

In the third comparison, the mechanical model for multilayer material systems is verified by applying it to the problem of EBPVD TBC spallation after cooling to room temperature. Whole new turbine blades were used for testing, which were coated with an EBPVD TBC comprising an YSZ ceramic TC layer, a TGO layer, and a Pt-diffused BC layer on the single crystal CMSX-4 Ni-based superalloy substrate. The thickness of the TC is $138 \mu \mathrm{m}$, and its Young's modulus through-thickness variation is described by

$$
\frac{E_{\mathrm{YSZ}}}{[\mathrm{GPa}]}=-8 \times 10^{-5} \frac{z_{\mathrm{YSZ}}^{3}}{\left[\mu \mathrm{m}^{3}\right]}+0.0192 \frac{z_{\mathrm{YSZ}}^{2}}{\left[\mu \mathrm{m}^{2}\right]}-1.5812 \frac{z_{\mathrm{YSZ}}}{[\mu \mathrm{m}]}+85.5850
$$


where $z_{\mathrm{YSZ}}=0$ is at the bottom of the TC and is positive upward, and the Poisson's ratio is $v_{\text {YSZ }}=0.2$ [28]. This through-thickness variation of Young's modulus is based on a polynomial fit to experimental results in Ref. [30] from testing the same TBC system after $120 \mathrm{~h}$ of isothermal heating at $1150{ }^{\circ} \mathrm{C}$. These results [30] and the polynomial fit are shown in

\section{Figure 3.}

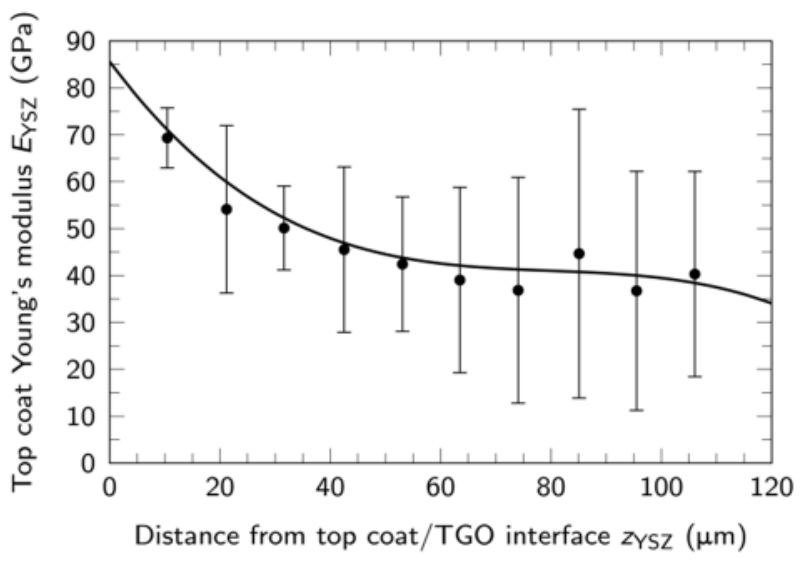

Figure 3 Through-thickness variation of Young's modulus in the YSZ ceramic TC layer after $120 \mathrm{~h}$ of isothermal heating at $1150{ }^{\circ} \mathrm{C}$ [30].

The thickness of the TGO is considered thin enough at $5 \mu \mathrm{m}$ to assume an average Young's modulus of $E_{\mathrm{TGO}}=400 \mathrm{GPa}$ with a Poisson's ratio of $v_{\mathrm{TGO}}=0.25$ [7,28]. Scanning electron microscope images, such as that in Figure 4, have identified that coating spallation of this TBC system occurs at the interface between the TGO and the BC. This also agrees with Refs. $[2,31,32]$. The blister layer is therefore a bi-layer consisting of the TC and the TGO. Note that although Figure 4 shows a wavy interface, its amplitude in comparison to the thickness of the combined TC and TGO (as the top layer in the developed mechanical model) is negligible and the flat-interface model is considered valid. Figure $\mathbf{4}$ is of a coupon sample cut from the pressure side of the blade. It was isothermally heated at $1135^{\circ} \mathrm{C}$ for $50 \mathrm{~h}$ and then naturally cooled to room temperature in the lab environment. The sample was embedded in epoxy and the cross-section was polished to a $1-\mu \mathrm{m}$ surface finish for observation. 


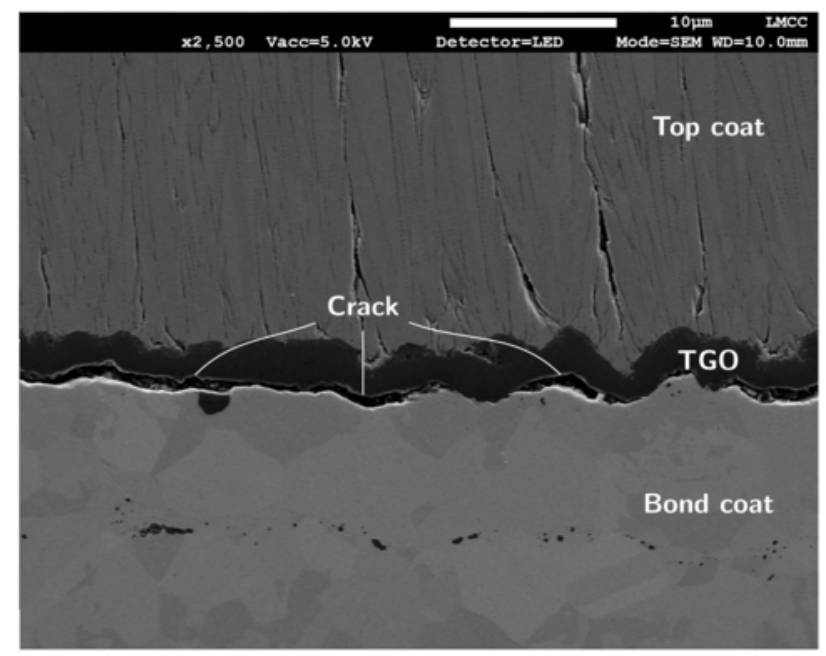

Figure 4 A representative scanning electron microscope image of a TBC coupon sample showing cracking between the TGO and the BC.

The stiffness per width of the top layer (i.e. the blister layer, comprising the TC and TGO) is given by Eq. (17): Extensional stiffness $A=14004.911 \mathrm{~N} \mathrm{~mm}^{-1}$, coupling stiffness $B=-117.521 \mathrm{~N}$ and bending stiffness $D=29.076 \mathrm{~N} \mathrm{~mm}$. Eq. (8) then gives $A^{*}=16912.560 \mathrm{~N} \mathrm{~mm}^{-1}$ and $B^{*}=-148.386 \mathrm{~N}$. The typical CTE mismatch between the top layer and the bottom layer (i.e. the $\mathrm{BC}$ and the substrate together) is $4 \mathrm{ppm}{ }^{\circ} \mathrm{C}^{-1}$ [4]. The modeI fracture toughness at the interface between the TGO and BC is $8.4 \mathrm{~J} \mathrm{~m}^{-2}$ [4] and the fracture toughness ratio $\psi$ is 5 [29].

Specimens were isothermally oxidized at $1135^{\circ} \mathrm{C}$ and cooled to room temperature at $25^{\circ} \mathrm{C}$ in the laboratory environment. For this $1110{ }^{\circ} \mathrm{C}$ of cooling, the biaxial compressive residual strain is calculated as $0.44 \%$. For the specific specimen described in this section, there were seven heating-cooling cycles (reaching a total $220 \mathrm{~h}$ of heating) until the convex surface spalled. The first heating period was for $100 \mathrm{~h}$, which then continued with a further six heatingcooling cycles of $20 \mathrm{~h}$. No spallation failure occurred during cooling, but after the seventh heating-cooling cycle, the convex surface of the blade spalled off shortly after reaching room temperature (i.e. at a constant biaxial compressive residual stress).

Note that eight new specimens in total were tested with slight variations in the procedure in order to establish the most effective technique. It was very challenging to record images over the whole curved surface of the blade, and over the whole duration of cooling and dwelling at room temperature. The results described here are for the single specimen which displayed both circular and straight blisters (and can therefore be modelled theoretically), and for which the whole spallation process was clearly captured. Qualitatively, however, all the specimens 
displayed the same spallation behavior, even though accurate measurements are not available for the reasons stated above.

Figure 5 shows a sequence of optical and processed images from Ref. [27], illustrating the nucleation, growth, branching, and spallation of a circular blister on the convex surface. Timing started when the specimen was removed from the furnace. The recording speed is 30 frames per second. The blister is visible due to the scattering of light from the surface (the top of each subfigure in Figure 5); however, to make the blister more prominent for easier blister radius measurements and for clearer presentation here, image (a) was subtracted from images (b) to (h) in post-processing to reveal just the difference between these images and image (a) (the bottom of each subfigure in Figure 5). The uncertainty in measuring the blister radius from these images is $0.1 \mathrm{~mm}$. 


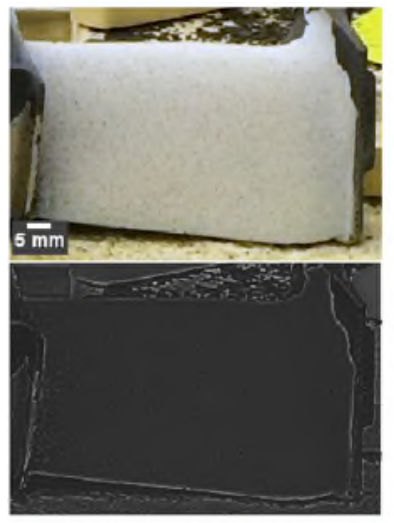

(a) $50 \mathrm{~min} 19 \mathrm{~s}$ frame $0 / 30$

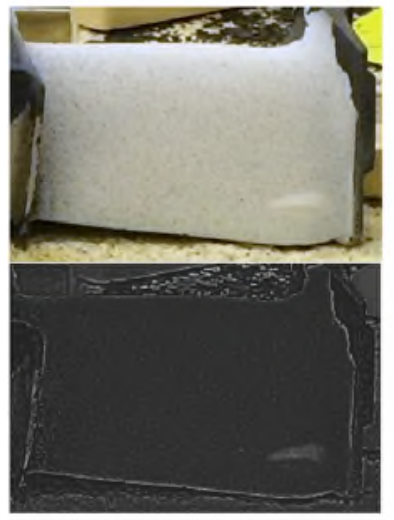

(e) $50 \mathrm{~min} 21 \mathrm{~s}$ frame $15 / 30$
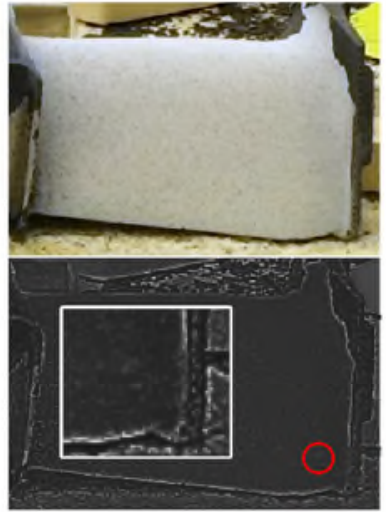

(b) $50 \mathrm{~min} 20 \mathrm{~s}$ frame $14 / 30$
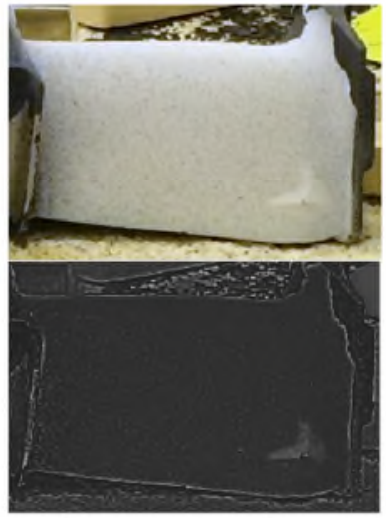

(f) $50 \mathrm{~min} 21 \mathrm{~s}$ frame $16 / 30$

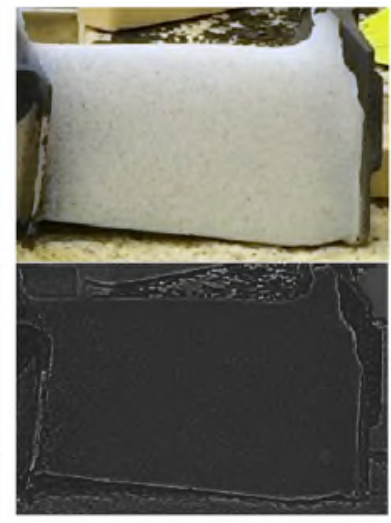

(c) $50 \min 21 \mathrm{~s}$ frame $13 / 30$
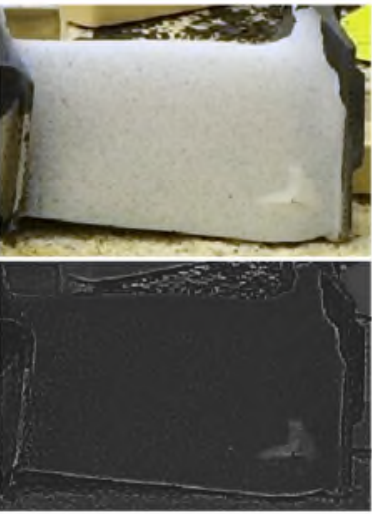

(g) $50 \min 21 \mathrm{~s}$ frame $20 / 30$

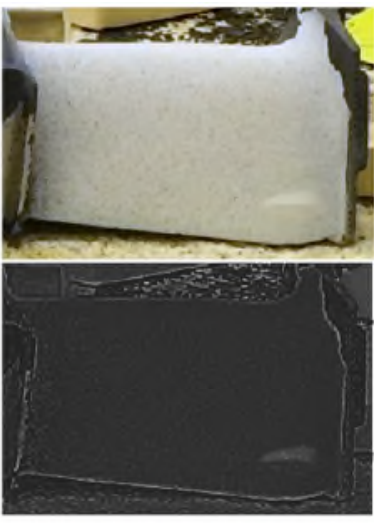

(d) $50 \mathrm{~min} 21 \mathrm{~s}$ frame $14 / 30$

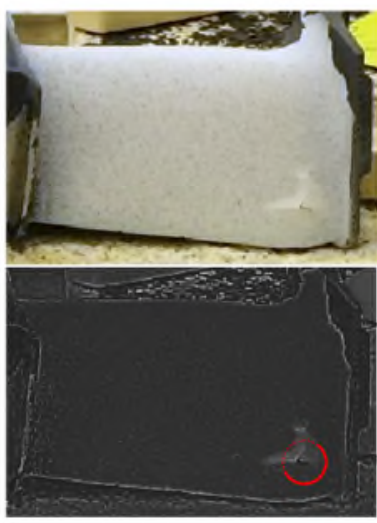

(h) $50 \mathrm{~min} 22 \mathrm{~s}$ frame $16 / 30$

Figure 5 Sequence of optical and processed images [27] showing the nucleation (b), stable growth (b-c) and unstable growth (c-g), branching (e-f) and spallation (h) of a blister on the convex surface of the turbine blade. The frame number is counted from the start of each second.

The just-discernible small spot (circled in red) in image (b) is clearly much smaller than the buckling radius of $2.38 \mathrm{~mm}$ that is calculated using the conventional buckling-driven approach with Eq. (41) and $\alpha=1.22$. This nucleation radius is difficult to see in a still image; it is much clearer to see by playing a video recording. A sharpened and magnified view is also provided in the insert in image (b). According to the PECs hypothesis, PECs are the source of energy that is required to nucleate the blister, which due to its size cannot be explained by the conventional buckling-driven approach. The required nucleation energy predicted by the mechanical model is given by Eq. (64).

After nucleation (b), the blister took about $1 \mathrm{~s}$ to grow steadily and its radius reached about $1.1 \mathrm{~mm}$ in (c), which is still smaller than the buckling radius of $2.38 \mathrm{~mm}$. According to the PECs hypothesis, the blister growth during this stage is being driven by PECs. 
One frame after image (c) (i.e. $0.033 \mathrm{~s}$ later), the blister suddenly grew into the non-circular shape in (d). This is considered to be unstable growth, which according to the PECs hypothesis is driven by both buckling and PECs. The radius for the initiation of the unstable growth is therefore taken as $1.1 \mathrm{~mm}$, as measured from (c). The corresponding radius from the mechanical model is given by Eq. (39), or by the approximate Eq. (41).

From image (c) onwards, the blister is viewed as having a circle-shaped part plus initially one branch (d-e) and then two branches (f-h). The circle-shaped part is very close to circular and it is natural to fit a circle to this part of the blister, as demonstrated in (h). Note that although the blister is strictly non-circular, it is not significantly less circular than some of the alumina scale blisters shown in Ref. [26], for which diameter measurements are still taken. By using this approach, the radius of the right half-circle in (d) is measured as $2.5 \mathrm{~mm}$, and in (e) as $2.8 \mathrm{~mm}$. Images (e) to (g) show further unstable growth of the blister, which according to the PECs hypothesis was still being driven by both PECs and buckling. One frame after (e) (i.e. $0.033 \mathrm{~s}$ later), the blister branched (f); however, the right half of the blister retained its circular shape with a radius of about $2.8 \mathrm{~mm}$. Following that, up until image $(\mathrm{h})$, the blister continued to grow rapidly and unstably in both branching directions and also radially in the right halfcircle area. The right half-circle radius in $(\mathrm{g})$ is measured as $3.1 \mathrm{~mm}$, and ridge cracks are also visible. In (h), the blister and ridge cracks have extended further still, and the radius of the right half-circle is measured as $3.3 \mathrm{~mm}$. Image (h) is regarded as the spallation radius since it represents the end of this period of rapid unstable growth. Note that the blister in (h) has not yet spalled off to expose the $\mathrm{BC}$ even though it has reached its spallation radius. This is because the blister energy cannot have been great enough to crack through the TGO and TC. $12 \mathrm{~s}$ after image (h), the branches extended very rapidly and detached from the substrate. This final stage of blister growth and spallation is considered later.

The measured radii are compared with the corresponding radius predictions from the mechanical model in Table 3. Note that $R_{\mathrm{B}}$ at spallation does not depend on $\alpha$, and so the predicted values are given only once in Table 3 and are not repeated for each value of $\alpha$. As before, 'E', 'T' and '2D' denote the use of classical plate partition theory, first-order sheardeformable plate partition theory, and 2D elasticity partition theory respectively in the mechanical model. In addition, $G_{\mathrm{c}}$ and $\Omega$ from the mechanical model with the $\mathrm{E}, \mathrm{T}$ and $2 \mathrm{D}$ theories are summarized in Table 4. These are the $\Omega$ values used in Table 3 to predict the initiation of unstable growth with Eqs. (39) and (41), and to predict the spallation radius with Eqs. (50) and (51). Based on $\xi=0.483$ for this experiment, the $\Omega$ values are all significantly 
larger than $2 \alpha^{2} \xi$ and $(1+\xi)$, as required by Eqs. (39) and Eq. (50) respectively; hence, Eqs. (41) and (51) give good approximations. Note that the predicted spallation radius is slightly smaller than the measured one. As discussed in Section 2.4.1, this may be because of the appearance of ridge cracks which consume a small amount of blister energy.

Table 3 Circular blister radius comparison for the initiation of unstable growth and spallation.

\begin{tabular}{|c|c|c|c|c|c|c|c|c|c|c|}
\hline \multirow[b]{3}{*}{$\alpha$} & \multicolumn{5}{|c|}{$R_{\mathrm{B}}$ at initiation of unstable growth $(\mathrm{mm})$} & \multicolumn{5}{|c|}{$R_{\mathrm{B}}$ at spallation (mm) } \\
\hline & \multicolumn{3}{|c|}{ Eq. (39) } & \multicolumn{2}{|l|}{ Eq. (41) } & \multicolumn{3}{|c|}{ Eq. (50) } & \multicolumn{2}{|c|}{ Eq. (51) } \\
\hline & $\mathrm{E}$ & $\mathrm{T}$ & $2 \mathrm{D}$ & All & $\begin{array}{l}\text { Test } \\
\text { data }\end{array}$ & $\mathrm{E}$ & $\mathrm{T}$ & $2 \mathrm{D}$ & All & $\begin{array}{l}\text { Test } \\
\text { data }\end{array}$ \\
\hline 0.652 & 1.28 & 1.28 & 1.28 & 1.27 & $1.1 \pm 0.1$ & & & & & $3.3 \pm 0.1$ \\
\hline 0.936 & 1.84 & 1.85 & 1.84 & 1.83 & image & 3.45 & 3.49 & 3.46 & 3.43 & image \\
\hline 1.22 & 2.40 & 2.43 & 2.41 & 2.38 & (c) & & & & & (h) \\
\hline
\end{tabular}

Table $4 G_{\mathrm{c}}, \lambda$, and $\Omega$ from the mechanical model based on the classical plate, first-order shear-deformable plate and 2D elasticity partition theories.

\begin{tabular}{ccc}
\hline & $G_{\mathrm{c}}\left(\mathrm{J} \mathrm{m}^{-2}\right)$ & $\Omega$ \\
& Eqs. $(31),(56),(59)$ & Eqs. (40), (57), (60) \\
\hline $\mathrm{E}$ & 8.400 & 23.966 \\
$\mathrm{~T}$ & 17.951 & 11.215 \\
2D & 10.683 & 18.845 \\
\hline
\end{tabular}

The lowest value of unstable growth radius predicted by the PEC-based mechanical model is $1.27 \mathrm{~mm}$ by taking $\alpha=0.652$. In contrast, the lowest value of unstable growth radius predicted by the conventional buckling-driven approach is slightly larger than $2.38 \mathrm{~mm}$, which is given by taking $\alpha=1.220$. The measured radius at the initiation of unstable growth is $1.1 \mathrm{~mm}$, which is close to the lowest value predicted by the PEC-based mechanical model.

The measured spallation radius is $3.3 \mathrm{~mm}$, which is close to the analytical prediction of $3.4 \mathrm{~mm}$ (independent of $\alpha$ ), despite the appearance of ridge cracks in (h). These experimental observations, together with their good agreement with the PEC-based mechanical model, strongly support the hypothesis that TBC spallation is driven by both PECs and buckling in what represents a new spallation mechanism. 
In the experiment, no straight blister nucleation or growth was observed; however, some straight-edged spallation did eventually occur, growing out of the top of the original blister, as shown in Figure 6 in image (i) of the sequence. The average half-width of the straight-edged spallation indicated on Figure 6 is $3.2 \mathrm{~mm}$. This frame is from just after the coating flaked off, and it is therefore considered to be the straight blister spallation half-width for this TBC. The corresponding half-width values from the mechanical model are compared in Table 5. Note the mechanical model predicts that the spallation half-width of a straight blister is identical to the spallation radius of a circular blister. The measured half-width of $3.2 \mathrm{~mm}$ is slightly smaller than the predicted value of $3.43 \mathrm{~mm}$. The difference is likely due to ridge cracking, which the current mechanical model does not consider; however, as discussed in Section 2.4.1, the predicted spallation half-width being slightly smaller than the measured one is consistent with ridge cracking consuming a small amount of blister energy.

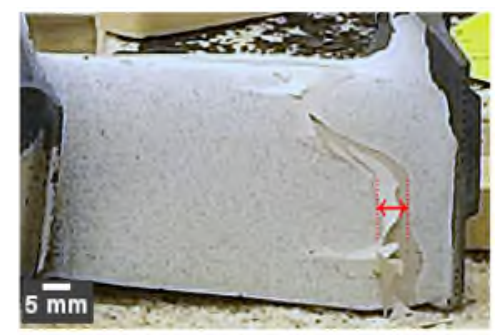

(i) $50 \mathrm{~min} 49 \mathrm{~s}$ frame $1 / 30$

Figure 6 Spallation of the left-half straight blister.

Table 5 Straight blister half-width comparison for spallation.

\begin{tabular}{|c|c|c|c|c|c|}
\hline & \multicolumn{3}{|c|}{ Eq. (50) } & \multicolumn{2}{|c|}{ Eq. (51) } \\
\hline & $\mathrm{E}$ & $\mathrm{T}$ & $2 \mathrm{D}$ & All & Test data \\
\hline Half-width (mm) & 3.45 & 3.49 & 3.46 & 3.43 & $3.2 \pm 0.1$ \\
\hline
\end{tabular}

\section{Conclusions}

TBC spallation failure reduces the reliability and durability of turbine blades on gas turbine engines. TBC blisters can develop with circular and straight delamination edges as well as with other more-complex shapes. To investigate the mechanics of TBC spallation, a whole new turbine blade with an EBPVD TBC was isothermally heated and cooled to room temperature in cycles. After a certain number of cycles, the TBC eventually spalled off shortly after reaching room temperature under constant biaxial compressive residual stress. The blister layer comprised the TC and TGO. The observed spallation sequence began with blister nucleation, 
which at first grew stably, and then grew unstably with branching, before the TBC finally flaked off. Blister nucleation occurred at a much smaller size than the critical buckling size, which proves that the spallation process cannot be explained by the conventional bucklingdriven approach.

The authors' PECs hypothesis [12,13] says that PECs provide the additional source of energy that is required for a blister to nucleate and grow. The conventional buckling-driven approach has no such requirement. A mechanical model based on this hypothesis of PECs was developed to explain and predict the experimental observations. The mechanical model accounts for arbitrary through-thickness variations of material properties and degree of cooling, which attempts to accurately capture the condition of a real turbine blade in cooling.

The blister sizes at the initiation of unstable growth and at spallation, as measured and as predicted by the mechanical model, are in close agreement. Moreover, the mechanical model provides two conditions for the spallation of TBCs: (1) PECs must be able to supply sufficient energy to take the blister energy to the blister energy capacity $\left(U_{\mathrm{a}}\right)_{\mathrm{MUE}}$ in Eq. (49). After this point, the blister has stored enough energy in itself to continue propagating with no further energy requirement. (2) The ratio between the in-plane strain energy per unit width and the interface adhesion toughness, $\Omega$, must be greater than $(1+\xi)$, where $\xi=\left(A D-B^{2}\right) /(2 A D)$ . These two conditions provide valuable guidance for TBC design and optimisation to avoid spallation failure.

The spallation behavior observations described above, together with the accuracy of the developed mechanical model, strongly suggest that a new mechanism of spallation has been discovered. It is now necessary to conduct further research to discover the source of PECs and their development under real operational conditions in order to improve the lifetime, lifetime variation, and operating temperature of turbine blades and other engine components with TBCs. When linked together with the source and development of PECs, this work is expected to provide the framework and understanding for significant improvements in future turbine blade design.

\section{Data availability}

The authors confirm that the data supporting the findings of this study are available within the article. 


\section{References}

[1] Clarke DR, Oechsner M, Padture NP. Thermal-barrier coatings for more efficient gasturbine engines. MRS Bull 2012;37:891-8. doi:10.1557/mrs.2012.232.

[2] Padture NP. Thermal Barrier Coatings for Gas-Turbine Engine Applications. Science (80- ) 2002;296:280-4. doi:10.1126/science.1068609.

[3] Liu Y, Vidal V, Roux S Le, Blas F, Ansart F, Lours P. Influence of isothermal and cyclic oxidation on the apparent interfacial toughness in thermal barrier coating systems. J Eur Ceram Soc 2015;35:4269-75. doi:10.1016/j.jeurceramsoc.2015.07.018.

[4] Zhao X, Liu J, Rickerby DS, Jones RJ, Xiao P. Evolution of interfacial toughness of a thermal barrier system with a Pt-diffused $\gamma / \gamma^{\prime}$ bond coat. Acta Mater 2011;59:6401-11. doi:10.1016/j.actamat.2011.07.001.

[5] Shen Q, Yang L, Zhou YC, Wei YG, Zhu W. Effects of growth stress in finitedeformation thermally grown oxide on failure mechanism of thermal barrier coatings. Mech Mater 2017;114:228-42. doi:10.1016/j.mechmat.2017.08.011.

[6] Chirivi L, Nicholls JR. Influence of Surface Finish on the Cyclic Oxidation Lifetime of an EB-PVD TBC, Deposited on PtAl and Pt-diffused Bondcoats. Oxid Met 2014;81:1731. doi:10.1007/s11085-013-9429-4.

[7] Busso EP, Qian ZQ, Taylor MP, Evans HE. The influence of bondcoat and topcoat mechanical properties on stress development in thermal barrier coating systems. Acta Mater 2009;57:2349-61. doi:10.1016/j.actamat.2009.01.017.

[8] Mumm DR, Evans AG. On the role of imperfections in the failure of a thermal barrier coating made by electron beam deposition. Acta Mater 2000;48:1815-27. doi:10.1016/S1359-6454(99)00473-5.

[9] Tolpygo VK, Clarke DR. On the rumpling mechanism in nickel-aluminide coatings: Part II: characterization of surface undulations and bond coat swelling. Acta Mater 2004;52:5129-41. doi:10.1016/j.actamat.2004.07.023.

[10] Wu LT, Wu RT, Xiao P, Osada T, Lee KI, Bai M. A prominent driving force for the spallation of thermal barrier coatings: Chemistry dependent phase transformation of the bond coat. Acta Mater 2017;137:22-35. doi:10.1016/j.actamat.2017.06.037.

[11] Vaidyanathan K. Surface geometry and strain energy effects in the failure of a (Ni,Pt)Al/EB-PVD thermal barrier coating. Acta Mater 2004;52:1107-15. doi:10.1016/j.actamat.2003.10.043.

[12] Wang S, Harvey CM, Wang B. Room temperature spallation of $\alpha$-alumina films grown 
by oxidation. Eng Fract Mech 2017;178:401-15. doi:10.1016/j.engfracmech.2017.03.002.

[13] Harvey CM, Wang B, Wang S. Spallation of thin films driven by pockets of energy concentration. Theor Appl Fract Mech 2017;92:1-12. doi:10.1016/j.tafmec.2017.04.011.

[14] Tolpygo VK, Clarke DR. Spalling failure of $\alpha$-alumina films grown by oxidation. II. Decohesion nucleation and growth. Mater Sci Eng A 2000;278:151-61. doi:10.1016/S0921-5093(99)00582-1.

[15] Tolpygo VK, Clarke DR. Spalling failure of $\alpha$-alumina films grown by oxidation: I. Dependence on cooling rate and metal thickness. Mater Sci Eng A 2000;278:142-50. doi:10.1016/S0921-5093(99)00581-X.

[16] Wang S, Harvey C. A theory of one-dimensional fracture. Compos Struct 2012;94:75867. doi:10.1016/j.compstruct.2011.09.011.

[17] Wang S, Harvey CM. Mixed mode partition theories for one dimensional fracture. Eng Fract Mech 2012;79:329-52. doi:10.1016/j.engfracmech.2011.11.013.

[18] Harvey CM, Wang S. Mixed-mode partition theories for one-dimensional delamination in laminated composite beams. Eng Fract Mech 2012;96:737-59. doi:10.1016/j.engfracmech.2012.10.001.

[19] Hutchinson JW, Suo Z. Mixed Mode Cracking in Layered Materials. Adv. Appl. Mech., vol. 29, 1991, p. 63-191. doi:10.1016/S0065-2156(08)70164-9.

[20] Harvey CM, Wood JD, Wang S, Watson A. A novel method for the partition of mixedmode fractures in 2D elastic laminated unidirectional composite beams. Compos Struct 2014;116:589-94. doi:10.1016/j.compstruct.2014.05.041.

[21] Wood JD, Harvey CM, Wang S. Partition of mixed-mode fractures in 2D elastic orthotropic laminated beams under general loading. Compos Struct 2016;149:239-46. doi:10.1016/j.compstruct.2016.04.016.

[22] Wang S, Harvey CM, Wang B, Watson A. Post-local buckling-driven delamination in bilayer composite beams. Compos Struct 2015;133:1058-66. doi:10.1016/j.compstruct.2015.08.012.

[23] Harvey CM, Eplett MR, Wang S. Experimental assessment of mixed-mode partition theories for generally laminated composite beams. Compos Struct 2015;124:10-8. doi:10.1016/j.compstruct.2014.12.064.

[24] Harvey CM, Wang S. Experimental assessment of mixed-mode partition theories. Compos Struct 2012;94:2057-67. doi:10.1016/j.compstruct.2012.02.007. 
[25] Wood JD, Harvey CM, Wang S. Adhesion toughness of multilayer graphene films. Nat Commun 2017;8:1952. doi:10.1038/s41467-017-02115-w.

[26] Zhu C, Zhao X, Molchan IS, Thompson GE, Liang G, Xiao P. Effect of cooling rate and substrate thickness on spallation of alumina scale on Fecralloy. Mater Sci Eng A 2011;528:8687-93. doi:10.1016/j.msea.2011.08.044.

[27] Yuan B, Harvey CM, Thomson RC, Critchlow GW, Wang S. A new spallation mechanism of thermal barrier coatings on aero-engine turbine blades. Theor Appl Mech Lett 2018;8:7-11. doi:10.1016/j.taml.2018.01.007.

[28] Liu D, Rinaldi C, Flewitt PEJ. Effect of substrate curvature on the evolution of microstructure and residual stresses in EBPVD-TBC. J Eur Ceram Soc 2015;35:256375. doi:10.1016/j.jeurceramsoc.2015.02.024.

[29] Fleck NA, Cocks ACF, Lampenscherf S. Thermal shock resistance of air plasma sprayed thermal barrier coatings. J Eur Ceram Soc 2014;34:2687-94. doi:10.1016/j.jeurceramsoc.2014.01.002.

[30] Zhao X, Wang X, Xiao P. Sintering and failure behaviour of EB-PVD thermal barrier coating after isothermal treatment. Surf Coatings Technol 2006;200:5946-55. doi:10.1016/j.surfcoat.2005.09.006.

[31] Meier SM, Nissley DM, Sheffler KD, Cruse TA. Thermal Barrier Coating Life Prediction Model Development. J Eng Gas Turbines Power-Transactions Asme 1992;114:258-63. doi:10.1115/91-GT-040.

[32] Strangman TE. Columnar grain ceramic thermal barrier coatings, 1982. 


\section{A new spallation mechanism of thermal barrier coatings and a generalized mechanical model}

Yuan, Bo

Elsevier

Yuan B, Harvey C, Thomson R, et al., (2019) A new spallation mechanism of thermal barrier coatings and a generalized mechanical model. Composite Structures, Volume 227, November 2019, Article number 111314

https://doi.org/10.1016/j.compstruct.2019.111314

Downloaded from Cranfield Library Services E-Repository 